\title{
Multiobjective Economic Load Dispatch Problem Solved by New PSO
}

\author{
Nagendra Singh ${ }^{1}$ and Yogendra Kumar ${ }^{2}$ \\ ${ }^{1}$ Department of Electrical Engineering, Mewar University, Chittorgarh, Rajasthan, India \\ ${ }^{2}$ Department of Electrical Engineering, Maulana Azad National Institute of Technology, Bhopal, India \\ Correspondence should be addressed to Nagendra Singh; nsingh007@rediffmail.com
}

Received 30 September 2014; Accepted 2 February 2015

Academic Editor: Nikos D. Lagaros

Copyright (c) 2015 N. Singh and Y. Kumar. This is an open access article distributed under the Creative Commons Attribution License, which permits unrestricted use, distribution, and reproduction in any medium, provided the original work is properly cited.

\begin{abstract}
Proposed in this paper is a new particle swarm optimization technique for the solution of economic load dispatch as well as environmental emission of the thermal power plant with power balance and generation limit constraints. Economic load dispatch is an online problem to minimize the total generating cost of the thermal power plant and satisfy the equality and inequality constraints. Thermal power plants use fossil fuels for the generation of power; fossil fuel emits many toxic gases which pollute the environment. This paper not only considers the economic load dispatch problem to reduce the total generation cost of the thermal power plant but also deals with environmental emission minimization. In this paper, fuel cost and the environmental emission functions are considered and formulated as a multiobjective economic load dispatch problem. For obtaining the solution of multiobjective economic load dispatch problem a new PSO called moderate random search PSO was used. MRPSO enhances the ability of particles to explore in the search spaces more effectively and increases their convergence rates. The proposed algorithm is tested for the IEEE 30 bus test systems. The results obtained by MRPSO algorithm show that it is effective and efficient.
\end{abstract}

\section{Introduction}

Electrical power system is a very large interconnected system. It plays very important role in the economy of the country. For the efficient and reliable operation of such large interconnected power system, it required proper analysis and the way to operate such system economically. Economic load dispatch problem is an important optimization task in the electrical power system and study of economic load dispatch helps to operate power systems economically with an efficient way and provide power without any interruption. The economic load dispatch is an online process of allocating generation among the available generating units to minimize the total generation cost and satisfy the equality and inequality constraints. Since the civilization increases day by day the demand of electricity increases in the same ratio. For the satisfaction of the load demand large numbers of thermal power plants are installed and the capacity of coal burnt also increases. Due to burning large amounts of coal emitted many toxic gases like carbon dioxide $\left(\mathrm{CO}_{x}\right)$, sulphur dioxide
$\left(\mathrm{SO}_{x}\right)$, and nitrogen oxides $\left(\mathrm{NO}_{x}\right)$ at thermal power plants and pollute the environment. Pollution is very harmful for the environment as well as living creatures. Environmental pollution increases the global warming and damage of the Ozone layer. So in recent trends it is required to generate the power with minimum cost and minimize the pollutant environment emission. The study of economic load dispatch helps to generate power on minimum cost and also reduce the environmental emission effects.

Many classical as well as modern techniques were used to solve economic load dispatch problem with environmental emission listed in the literature. Different methods have been reported in the literature for solving ELD problem as multiobjective problem. Talaq et al. [1] give a deep summary of economic load dispatch with environmental constraints. Linear programming techniques were proposed by Farag et al. [2] for the solution of ELD problem incorporated with environmental emission. They solved ELD problem as multiobjective problem with constraints. Authors of [3] proposed direct Newton-Raphson method for the solution of 
the multiobjective ELD problem in 2003. Goal programming approach was proposed by Nanda et al. [4] for the solution of ELD problem with emission constraints. Yokoyama et al. [5] presented multiobjective economic power generation dispatch based on probability security criteria. Multiobjective ELD problem with security constraint proposed by Chang et al. [6] was solved by using bicriterion global optimization techniques. Granelli et al. [7] presented emission constrained dynamic ELD. New stochastic search technique was proposed by Das and Patvardhan [8] for the multiobjective economic load dispatch problem. Some authors have proposed modern heuristic techniques such as fuzzy logic optimization technique [9] proposed for solution of multiobjective generation schedule. Genetic algorithm techniques were proposed by Xu et al. [10] to solve constrained multiobjective ELD problem. Particle swarm optimization techniques were proposed [11, 12] for obtaining multiple objectives.

Evolutionary programming technique was suggested by Suganya et al. [13] for multiobjective economic/emission load dispatch problem. Advanced MOEPSO-based multiobjective environmental, economic load dispatching was given by Mori and Okawa [14]. Abido [15] proposed multiobjective evolutionary algorithms for the electric power dispatch problem. Dutta and Sinha [12] suggested PSO technique for the solution of environmental economic dispatch problem with voltage stability constraint. Kennedy and Eberhart [16] for the first time in 1995 introduced particle swarm optimization (PSO) technique. It is a population-based evolutionary technique, inspired by the social behaviour of a flock of birds searching for food. The PSO algorithm simulates social behaviour among the particles flying in a multidimensional search space. In comparison with other evolutionary optimization techniques the PSO has a superior search performance with faster and more stable convergence rates. PSO is a very popular optimization technique between the researchers and many of the researchers used it for the solution of multiobjective economic load dispatch problem, but PSO has a drawback that it lacks global search ability in the last stage of iterations. So PSO is unable to give the global optimal solution for the multiobjective economic load dispatch problem. This problem of PSO may be overcome by using proposed MRPSO, because the MRPSO enhances the ability of particles to explore the solution spaces more effectively and increases their convergence rates. The proposed algorithm is tested on the IEEE 30 bus test systems. The results obtained by MRPSO algorithm show that it is practically efficient.

The multiobjective problem considered in this paper is solved by PSO and MRPSO with generation limit and power balance constraints. This study involves the solution of two objectives; the first of these is to minimize the total generation cost of generating units and second aspect is to minimize the environmental emission of thermal power plant. Effectiveness and efficiency of the proposed PSO technique were tested for the data of IEEE 30 bus network. Results obtained by PSO and MRPSO techniques were compared with other optimization techniques listed in the literature and it is found that MRPSO gives superior results compared to other techniques.

\section{Mathematical Model of Objective Function and Constraints}

In this paper two objective functions were considered. First objective is to minimize the total generation cost of generating power plant and the second objective is to minimize the environmental emission of the generating plants.

\subsection{Objective I}

Economic Generation Cost Function. Generation quadratic fuel cost characteristic of generating power plant is formulated as follows:

$$
\begin{gathered}
F_{T}=\operatorname{Min} f(\mathrm{FC}), \\
f(\mathrm{FC})=\sum_{i=1}^{N} a_{i} P_{i}^{2}+b_{i} P_{i}+c_{i},
\end{gathered}
$$

where $F_{T}$ is the total fuel cost, $f(\mathrm{FC})$ is the fuel cost function, $a_{i}, b_{i}$, and $c_{i}$ are the cost coefficients of the $i$ th generator, $P_{i}$ is the generated power of $i$ th power plants, and $N$ is the number of generators.

\subsection{Objective II}

Emission Objective Function. In this paper environmental emission was evaluated with consideration of $\mathrm{NO}_{x}$ gas. A typical $\mathrm{NO}_{x}$ emission at thermal power plants [12] can be formulated as shown in (2). Consider the following:

$$
\begin{gathered}
E_{T}=\operatorname{Min} \sum_{i=1}^{N} f\left(E_{i}\left(P_{i}\right)\right), \\
E_{i}\left(P_{i}\right)=\left(\alpha_{i}+\beta_{i} P_{i}+\gamma_{i} P_{i}^{2}\right)+\xi_{i} \sin \left(\lambda_{i} P_{i}\right) .
\end{gathered}
$$

Now both objectives may be combined in a single objective as given in (4), (5), and (6). The generation cost of each generator was evaluated at its maximum output:

$$
F_{i}\left(P_{i \max }\right)=\left(a_{i} P_{i \max }^{2}+b_{i} P_{i \max }+c_{i}\right) .
$$

$\mathrm{NO}_{x}$ emission of each generator at its maximum output was evaluated:

$$
E_{i}\left(P_{i \max }\right)=\left(\alpha_{i}+\beta_{i} P_{i \max }+\gamma_{i} P_{i \max }^{2}\right)+\xi_{i} \sin \left(\lambda_{i} P_{i \max }\right) .
$$

By (4) and (5) get

$$
\frac{F_{i}\left(P_{i \max }\right)}{E_{i}\left(P_{i \max }\right)}=k_{i} .
$$

So the final objective incorporated total generation cost and environmental emission generation which is given as

$$
F_{\text {final_object }}=F_{T}+k_{i}\left(E_{T}\right) \text {, }
$$

where $E_{T}$ is the total emission, $F_{T}$ is the total generation cost, $f\left(E_{i}\left(P_{i}\right)\right)$ is the emission function, and $\alpha_{i}, \beta_{i}, \gamma_{i}, \xi_{i}$, and $\lambda_{i}$ are the emission coefficients of the $i$ th generators. 


\subsection{Constraints}

2.3.1. Power Balance Constraints. The total generated power should be equal to the sum of total load demand and line loss. It can be formulated as (8). Consider the following:

$$
\begin{gathered}
\sum_{i=1}^{n} P_{i}=P_{D}+P_{L}, \\
P_{L}=\sum_{i=1}^{n} \sum_{j=1}^{n} P_{i} B_{i j} P_{j},
\end{gathered}
$$

where $P_{D}$ and $P_{L}$ are the total system demand and line loss, respectively, and $B_{i j}$ is the line loss elements.

2.3.2. Generator Limits. Generating output of each generating unit should lie between the maximum and minimum limits as given in

$$
P_{i}^{\min } \leq P_{i} \leq P_{i}^{\max },
$$

where $P_{i}$ is the output power of $i$ th generator and $P_{i}^{\min }$ and $P_{i}^{\max }$ are the minimum and maximum generated power of $i$ th generator, respectively.

\section{Overview of PSO Strategies}

This section represents a review of particle swarm optimization techniques which will serve as a performance measured for the PSO with moderate random search technique (MRPSO) [17] applied in this paper for solving of multiobjective ELD problem.

3.1. Particle Swarm Optimization. PSO is a very popular optimization technique and is used to solve optimization problems. It is a population-based optimization technique and it is motivated by the behaviour of social systems such as fish schooling and birds flocking. Particle swarm optimization was first introduced by Kennedy and Eberhart in the year 1995 [16]. It is a simple and powerful optimization tool which scatters random particles into the search space. Randomly initialized particles are called swarms; collect the information from each array of the problem constructed by their respective positions. The position of the particles is updated by using the velocityof particles. Both position and velocity are updated in a heuristic manner by using guidance from particles by their own experience and the experience of its neighbor's particles.

PSO randomly starts within the limits of maximum and minimum value of the power of the $i$ th generator. The position and velocity of the $i$ th particle of a $d$-dimensional search space can be represented in the following:

$$
\begin{aligned}
P_{i} & =\left(P_{i 1}, P_{i 2}, \ldots, P_{i d}\right), \\
V_{i} & =\left(V_{i 1}, V_{i 2}, \ldots, V_{i d}\right) .
\end{aligned}
$$

The best previous position of a particle is recorded and is represented as given in the following:

$$
P_{\text {best }}=\left(P_{i 1}, P_{i 2}, \ldots, P_{i d}\right) .
$$

If the $g$ th particle is the best among all particles in the group so far, it is represented as

$$
P_{g_{\text {best }}}=g_{\text {best }}=\left(P_{g 1}, P_{g 2}, \ldots, P_{g d}\right) .
$$

Velocity and position of the particle are updated by using

$$
\begin{gathered}
V_{i}^{(K+1)}=W * V_{i}^{K}+c_{1} * \operatorname{rand}_{1} \times\left(P_{\text {best } i}-S_{i}^{K}\right) \\
+c_{2} * \operatorname{rand}_{2} \times\left(g_{\text {best }}-S_{i}^{K}\right), \\
S_{i}^{(K+1)}=S_{i}^{K}+V_{i}^{K+1},
\end{gathered}
$$

where $V_{i}^{K}$ is velocity of the particles at iteration $K, W$ is the inertia weigh, $c_{1}$ and $c_{1}$ are the acceleration coefficients, rand $_{1}$ and rand $_{2}$ are the random numbers between 0 and $1, S_{i}^{K}$ is the current position of particle at iteration $K, P_{\text {best }}$ is the best position of individual $i$ th particle, and $g_{\text {best }}$ is the global best position of the group.

The acceleration coefficients $c_{1}$ and $c_{2}$ pull each particle towards $P_{\text {best }}$ and $g_{\text {best }}$ positions and $W$ is the inertia weight parameter which provides a balance between global and local explorations. Since $W$ decreases linearly from about 0.9 to 0.4 quite often during a run, the weighing function can be formulated as given in the following:

$$
W=W_{\max }-\frac{W_{\text {max }}-W_{\text {min }}}{\text { iter }_{\text {max }}} * \text { iter }
$$

where $W_{\max }$ and $W_{\min }$ are the initial and final inertia weight parameter, respectively, itermax is the maximum number of iterations, and iter is the current iteration position.

3.2. Moderate Random Search Particle Swarm Optimization (MRPSO). PSO is a very simple and popular optimization tool used for solving the ELD problem but it has some disadvantages also, such that PSO lacks global search ability at the last stage of iterations. So it is unable to give the global optimal solution of the ELD problem. In the year of 2011 [17] Gao and $\mathrm{Xu}$ first introduced the PSO with moderate random search technique called MRPSO. Moderate random search strategy enhances the global search ability of the particles. It can overcome the problem of PSO and gives the optimal solution for the proposed multiobjective ELD problem. In case of PSO, it is required to update the position and velocity of the particle, but after some iteration the velocity of particles should be zero so that in case of the MRPSO position of the particle can be updated as given in (17). If the particle's position is updated as given in (17) particles velocity does not change and it gives the global solution of the problem.

In MRPSO technique the particles are randomly generated for a population size within the range of $0-1$ same as in case of basic PSO and it is located within the maximum and minimum operating range of the generators as given in the following:

$$
P_{\text {Initial }}=P_{i \text { min }}+\operatorname{rand}\left(P_{i \max }-P_{i \min }\right),
$$

where $P_{\text {Initial }}$ is the initially generated particles, rand is random value between 0 and 1 , and $P_{i \max }$ and $P_{i \text { min }}$ are the maximum and minimum value of generated power of generator, respectively. 
The position of the particles is updated for the $i$ th particle at the $(K+1)$ th iteration using $(17)$. Consider the following:

$$
\begin{array}{r}
S_{i}^{K+1}=P_{d}+\alpha \lambda\left(m_{\text {best }_{i}}-S_{i}^{K}\right), \\
m_{\text {best }_{i}}=\sum_{i=1}^{N} \frac{P_{\text {best }}}{N},
\end{array}
$$

where $N$ is the population size in the MRPSO.

The parameter $\alpha$ used in (17) may be considered as a constant value between 0.45 and 0.35 oris obtained by changing $\alpha$ from 0.45 to 0.35 with the linear-decreasing method during iteration. $P_{d}$ is theattractor moving direction of particles; it is given as

$$
P_{d}=\operatorname{rand}_{0} P_{\text {best }}+\left(1-\operatorname{rand}_{0}\right) g_{\text {best }},
$$

where $\operatorname{rand}_{0}$ is a uniformly distributed random variable within $0-1, P_{\text {best }}$ is the best value of particle, and $g_{\text {best }}$ is the best value of $P_{\text {best }}$ values:

$$
\lambda=\frac{\operatorname{rand}_{1}-\operatorname{rand}_{2}}{\operatorname{rand}_{3}},
$$

where rand $_{1}$ and rand $_{2}$ are two random variables within $[0,1]$ and rand $_{3}$ is a random variable within $[-1,1]$.

\section{Algorithm of MRPSO for Multiobjective Economic Load Dispatch Problem}

In this paper PSO with the moderate random search technique (MRPSO) is used to solve multiobjective ELD problem. The study carries two objectives; the first objective is to minimize the total generation cost and the second objective is to reduce the environmental emission of the thermal power plant. The following steps are being used to solve the proposed multiobjective problem by using MRPSO.

Step 1. Select the constants.

Step 2. Initialize the swarm. First of all particles are randomly generated for a population size in the range $0-1$ and located between the maximum and the minimum operating limits of the generators as given in (16).

Step 3. Initialize velocity and position for all particles randomly set to within their minimum and maximum limits.

Step 4. Set generation counter: counter $=$ counter +1 .

Step 5. Evaluate the fitness for each particle according to the proposed objective function.

Step 6. Compare particles fitness evaluation with its personal best $\left(P_{\text {best }}\right)$ and global best $\left(g_{\text {best }}\right)$.

Step 7. Update position of particles by using (17).

Step 8. Apply stopping criteria. Number of iterations is the stopping criteria taken in this study. Means when number of iterations will completed the conversion of algorithm stopped.
TABLE 1: Cost coefficient with generation limits of IEEE 30 bus, 6 generating unit systems, and load demand $=283.4 \mathrm{MW}$.

\begin{tabular}{lccccc}
\hline Bus number & $a_{i}$ & $b_{i}$ & $c_{i}$ & $P_{\min }$ & $P_{\max }$ \\
\hline 1 & 100 & 200 & 10 & 50 & 200 \\
2 & 120 & 150 & 10 & 20 & 80 \\
5 & 40 & 180 & 20 & 15 & 50 \\
8 & 60 & 100 & 10 & 10 & 35 \\
11 & 40 & 180 & 20 & 10 & 30 \\
13 & 100 & 150 & 10 & 12 & 40 \\
\hline
\end{tabular}

TABLE 2: Environmental emission coefficients of IEEE 30 bus systems.

\begin{tabular}{lccccc}
\hline Bus number & $\alpha_{i}$ & $\beta_{i}$ & $\gamma_{i}$ & $\xi_{i}$ & $\lambda_{i}$ \\
\hline 1 & 4.091 & -5.554 & 6.490 & $2 * 10^{-4}$ & 2.857 \\
2 & 2.543 & -6.047 & 5.638 & $5 * 10^{-4}$ & 3.333 \\
5 & 4.258 & -5.094 & 4.586 & $1 * 10^{-6}$ & 8.00 \\
8 & 5.426 & -3.556 & 3.380 & $2 * 10^{-3}$ & 2.00 \\
11 & 4.258 & -5.094 & 4.586 & $1 * 10^{-6}$ & 8.000 \\
13 & 6.131 & -5.555 & 5.151 & $1 * 10^{-5}$ & 6.667 \\
\hline
\end{tabular}

TABLE 3: Line loss coefficients of line loss of IEEE 30 bus systems.

\begin{tabular}{lccccc}
\hline 0.0218 & 0.0107 & -0.00036 & -0011 & 0.00055 & 0.0033 \\
0.0107 & 0.0107 & -0.0001 & -0079 & 0.00026 & 0.0028 \\
-0.0004 & -.0002 & 0.02459 & -0133 & -0.0118 & -0.0079 \\
-0.0011 & -0.0018 & -0.01328 & 0.0265 & 0.0098 & 0.0045 \\
0.00055 & 0.00026 & 0.0118 & 0.0098 & 0.0216 & -0.0001 \\
0.0033 & 0.0028 & -00792 & 0.0045 & -.00012 & 0.02978 \\
\hline
\end{tabular}

\section{Problem Formulation and Results}

The proposed algorithms are tested for the data of standard IEEE 30 bus, 6 generator systems [12]. The MRPSO has been applied for solving IEEE 30 bus system for the demand of 283.4 MW. Data of IEEE 30 bus cost coefficients are given in Table 1, and the data of emission coefficients are given in Table 2, respectively. Table 3 shows the value of line loss coefficients ( $B$-coefficient).

Table 4 shows the results obtained by PSO [16], WIPSO [18], and MRPSO [17] without considering line loss.

Table 5 shows the result obtained by different PSO techniques considered by line loss. Constant used in this study for solving multiobjective ELD problem is shown in Table 6.

To assess the effectiveness and the efficiency of the proposed MRPSO algorithm for solving multiobjective ELD problem in this paper, a case study of IEEE 30 bus system with 6 generating units and their loss coefficients was taken. All data were considered from [12]. Different PSO techniques such as PSO, CPSO, WISPO, and MRPSO were used to solve the multiobjective ELD problem for the given data in Tables 1,2 , and 3. All PSO techniques were run on a $1.4 \mathrm{GHz}$, core- 2 solo processor with 2 GB DDR RAM.

Each PSO technique was tested for 100 numbers of iteration and for 20 population sizes. The robustness of the proposed algorithms is judged in each case of 100 trials. 
TABLE 4: Conversion results of IEEE 30 bus systems for the load of 283.4 MW without line loss.

\begin{tabular}{lcccc}
\hline Unit power output & PSO & CPSO & WIPSO & MRPSO \\
\hline P1 (MW) & 81.047 & 78.043 & 83.0324 & 73.0231 \\
P2 (MW) & 63.1092 & 63.0197 & 60.0947 & 62.1528 \\
P5 (MW) & 45.6863 & 48.632 & 44.023 & 46.8732 \\
P8 (MW) & 32.6824 & 34.0721 & 33.7961 & 34.0872 \\
P11 (MW) & 32.1054 & 27.0921 & 32.0823 & 28.4035 \\
P13 (MW) & 28.731 & 32.5401 & 30.432 & 38.8732 \\
Total power output & 283.361 & 283.399 & 283.460 & 283.413 \\
Fuel cost $(\$ /$ h) & 1434747 & 1411729. & 1429850 & 1364072 \\
Environmental emission (Ton/h) & 85137.024 & 83500.458 & 85265.256 & 79847.867 \\
Total cost $(\$ / h)$ & $16.69 * 10^{5}$ & $16.44 * 10^{5}$ & $16.66 * 10^{5}$ & $15.87 * 10^{5}$ \\
Time (sec) & 0.4302 & 0.42804 & 0.42401 & 0.40702 \\
\hline
\end{tabular}

TABLE 5: Conversion results of IEEE 30 bus systems for the load of 283.4 MW with line loss.

\begin{tabular}{lcccc}
\hline Unit power output & PSO & CPSO & WIPSO & MRPSO \\
\hline$P 1(\mathrm{MW})$ & 147.03 & 146.034 & 147.581 & 46.889 \\
$P 2(\mathrm{MW})$ & 43.114 & 46.0732 & 47.0705 & 43.0912 \\
$P 5(\mathrm{MW})$ & 36.661 & 34.0742 & 16.7863 & 43.07654 \\
$P 8(\mathrm{MW})$ & 23.019 & 26.0198 & 24.7219 & 24.0763 \\
$P 11(\mathrm{MW})$ & 25.377 & 24.108 & 19.8925 & 23.1732 \\
$P 13(\mathrm{MW})$ & 27.632 & 26.0911 & 19.5407 & 23.0453 \\
Loss $(\mathrm{MW})$ & 19.435 & 19.0003 & 302.9407 & 18.8468 \\
Total power output & 302.835 & 302.400 & 2661326.7 & 302.2468 \\
Fuel cost $(\$ / \mathrm{h})$ & 2617397.1 & 2607622.2 & 167729.08 & 2575426.4 \\
Environmental emission $(\mathrm{Ton} / \mathrm{h})$ & 163675.87 & 162228.52 & $30.91 * 10^{5}$ & 162153.591 \\
Total cost $(\$ / \mathrm{h})$ & $30.41 * 10^{5}$ & $30.31 * 10^{5}$ & 0.49541 & $29.96 * 10^{5}$ \\
Time $(\mathrm{sec})$ & 0.5165 & 0.5032 & & $\mathbf{0 . 4 8 2 0 3}$ \\
\hline
\end{tabular}

TABLE 6: Constant used to solve the proposed problem using MRPSO.

\begin{tabular}{lcc}
\hline S. number & Constants & Value of constant \\
\hline 1 & $C_{1}=C_{2}$ & 2 \\
2 & $\mathrm{~A}$ & 0.35 \\
3 & $W_{\max }$ & 0.9 \\
4 & $W_{\min }$ & 0.4 \\
\hline
\end{tabular}

Optimum results obtained by different PSO techniques are mentioned in Tables 4 and 5.

It is observed that for more than 100 trials the values obtained by different techniques were repeated and hence consider best results obtained in 100 trials. The optimal result obtained by MRPSO for the load of 283.4 MW without line loss is shown in Table 4: fuel cost of $\$ 1364072 / \mathrm{h}$, environmental emission cost of $79847.867 \mathrm{Kg} / \mathrm{h}$, and total cost including environmental emission of $\$ 15.87 * 10^{5} / \mathrm{h}$. The best result obtained by using MRPSO with considering the line loss is shown in Table 5, getting a fuel cost of $\$ 2575430 / \mathrm{h}$, environmental emission cost of $162153.96 \mathrm{Kg} / \mathrm{h}$, total cost including environmental emission of $\$ 29.967 * 10^{5} / \mathrm{h}$, and line loss of $18.8468 \mathrm{MW}$. Results obtained by MRPSO are less than other optimization techniques in both of the cases, that is, without line loss and with line loss. The convergence time taken by MRPSO is also less as compared to other PSO techniques.

\section{Conclusion}

Analysis of the economic load dispatch has a wide range of scope nowadays. Satisfying the load demand in minimum fuel cost is a great challenge for the power system. The optimal results obtained by the different PSO techniques are shown in Tables 4 and 5. Results obtained by different PSO techniques are shown in Tables 4 and 5. The fuel cost of the IEEE 30 bus system obtained by MRPSO is $\$ 1364072 / \mathrm{h}$ and environmental emission is $79847.867 \mathrm{Ton} / \mathrm{h}$, and total cost (fuel cost + environmental emission) is $\$ 15.87 * 10^{5} / \mathrm{h}$ without considering line loss. Fuel cost is $\$ 1364072 / \mathrm{h}$, environmental emission is $162153.591 \mathrm{Ton} / \mathrm{h}$, and total cost is $\$ 29.96 * 10^{5} / \mathrm{h}$ with consideration of line loss. It shows that the results of MRPSO algorithm are better than other PSO techniques and it takes minimum convergence time. So MRPSO is the better approach when compared to other PSO techniques mentioned in this paper. Results obtained by MRPSO show that it is an effective and efficient method for obtaining the result of optimization problem. 


\section{Conflict of Interests}

The authors declare that there is no conflict of interests regarding the publication of this paper.

\section{References}

[1] J. H. Talaq, F. El-Hawary, and M. E. El-Hawary, "A summary of environmental/economic dispatch algorithms," IEEE Transactions on Power Systems, vol. 9, no. 3, pp. 1508-1516, 1994.

[2] A. Farag, S. Al-Baiyat, and T. C. Cheng, "Economic load dispatch multiobjective optimization procedures using linear programming techniques," IEEE Transactions on Power Systems, vol. 10, no. 2, pp. 731-738, 1995.

[3] S.-D. Chen and J.-F. Chen, "A direct Newton-Raphson economic emission dispatch," International Journal of Electrical Power \& Energy System, vol. 25, no. 5, pp. 411-417, 2003.

[4] J. Nanda, D. P. Kothari, and K. S. Lingamurthy, "Economicemission load dispatch through goal programming technique," IEEE Transactions on Energy Conversion, vol. 3, no. 1, pp. 26-32, 1988.

[5] R. Yokoyama, S. H. Bae, T. Morita, and H. Sasaki, "Multiobjective generation dispatch based on probability security criteria," IEEE Transactions on Power Systems, vol. 3, no. 1, pp. 317-324, 1988.

[6] C. S. Chang, K. P. Wong, and B. Fan, "Security-constrained multiobjective generation dispatch using bicriterion global optimisation," IEE Proceedings: Generation, Transmission and Distribution, vol. 142, no. 4, pp. 406-414, 1995.

[7] G. P. Granelli, M. Montagna, G. L. Pasini, and P. Marannino, "Emission constrained dynamic dispatch," Electric Power Systems Research, vol. 24, no. 1, pp. 55-64, 1992.

[8] C. B. Das and C. Patvardhan, "New multi-objective stochastic search technique for economic load dispatch," IEE ProceedingsGeneration, Transmission and Distribution, vol. 145, no. 6, pp. 747-752, 1998.

[9] D. Srinivasan, C. S. Chang, and A. C. Liew, "Multiobjective generation scheduling using fuzzy optimal search technique," IEE Proceedings Generation, Transmission and Distribution, vol. 141, no. 3, pp. 233-242, 1994.

[10] J. X. Xu, C. S. Chang, and X. W. Wang, "Constrained multiobjective global optimisation of longitudinal interconnected power system by genetic algorithm," IEE Proceedings-Generation, Transmission and Distribution, vol. 143, no. 5, pp. 435-446, 1996.

[11] C. A. Coello Coello, G. T. Pulido, and M. S. Lechuga, "Handling multiple objectives with particle swarm optimization," IEEE Transactions on Evolutionary Computation, vol. 8, no. 3, pp. 256-279, 2004.

[12] P. Dutta and A. K. Sinha, "Environmental economic dispatch constrained by voltage stability using PSO," in Proceedings of the IEEE International Conference on Industrial Technology (ICIT '06), pp. 1879-1884, December 2006.

[13] G. Suganya, K. Balamurugan, and V. Dharmalingam, "Multi-objective evolutionary programming technique for economic/emission load dispatch," in Proceedings of the 1st International Conference on Advances in Engineering, Science and Management (ICAESM '12), pp. 269-275, Tamil Nadu, India, March 2012.

[14] H. Mori and K. Okawa, "Advanced MOEPSO-based multiobjective environmental economic load dispatching," in Proceedings of the IEEE Power and Energy Society General Meeting, pp. 1-7, IEEE, Minneapolis, Minn, USA, July 2010.
[15] M. A. Abido, "Multiobjective evolutionary algorithms for electric power dispatch problem," IEEE Transactions on Evolutionary Computation, vol. 10, no. 3, pp. 315-329, 2006.

[16] J. Kennedy and R. C. Eberhart, "Particle swarm optimization," in Proceedings of the IEEE International Conference on Neural Networks, vol. 4, pp. 1942-1948, December 1995.

[17] H. Gao and W. Xu, "A new particle swarm algorithm and its globally convergent modifications," IEEE Transactions on Systems, Man, and Cybernetics, Part B: Cybernetics, vol. 41, no. 5, pp. 1334-1351, 2011.

[18] P. T. Vu, D. L. Le, N. D. Vo, and J. Tlusty, "A novel weightimproved particle swarm optimization algorithm for optimal power flow and economic load dispatch problems," in Proceedings of the IEEE PES Transmission and Distribution Conference and Exposition, pp. 1-7, April 2010. 

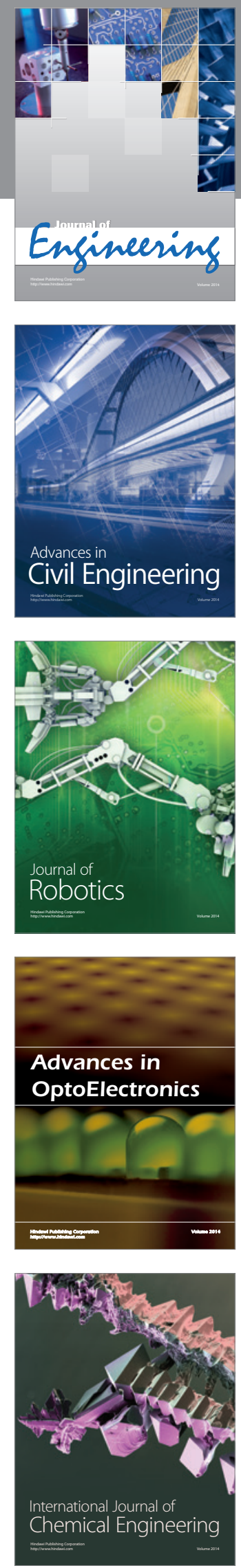

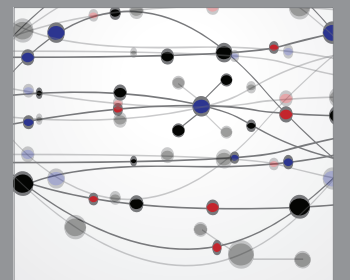

The Scientific World Journal
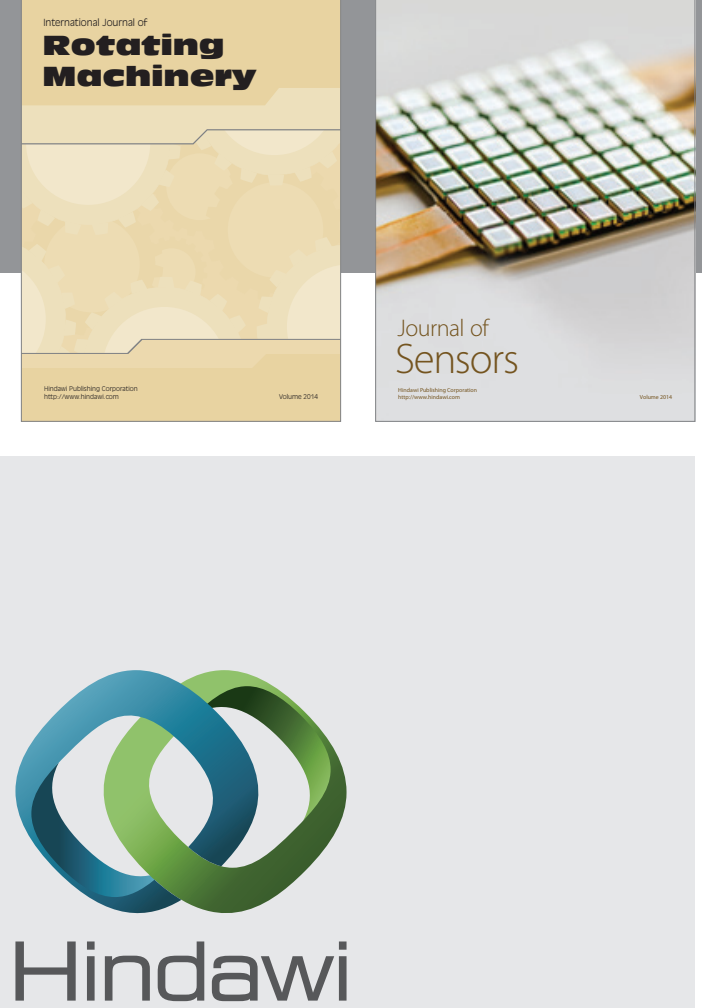

Submit your manuscripts at http://www.hindawi.com
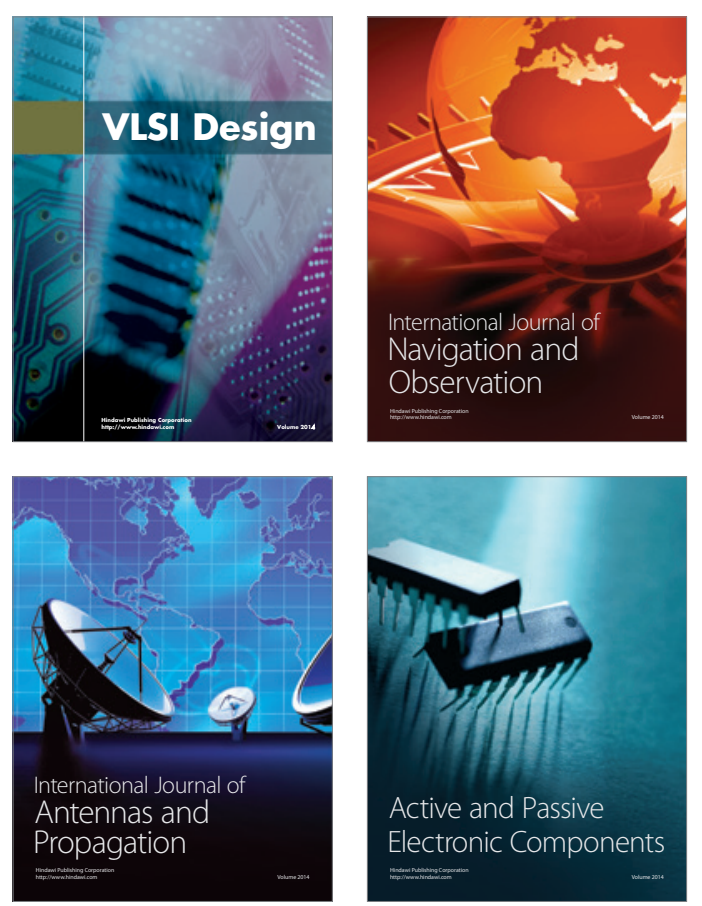
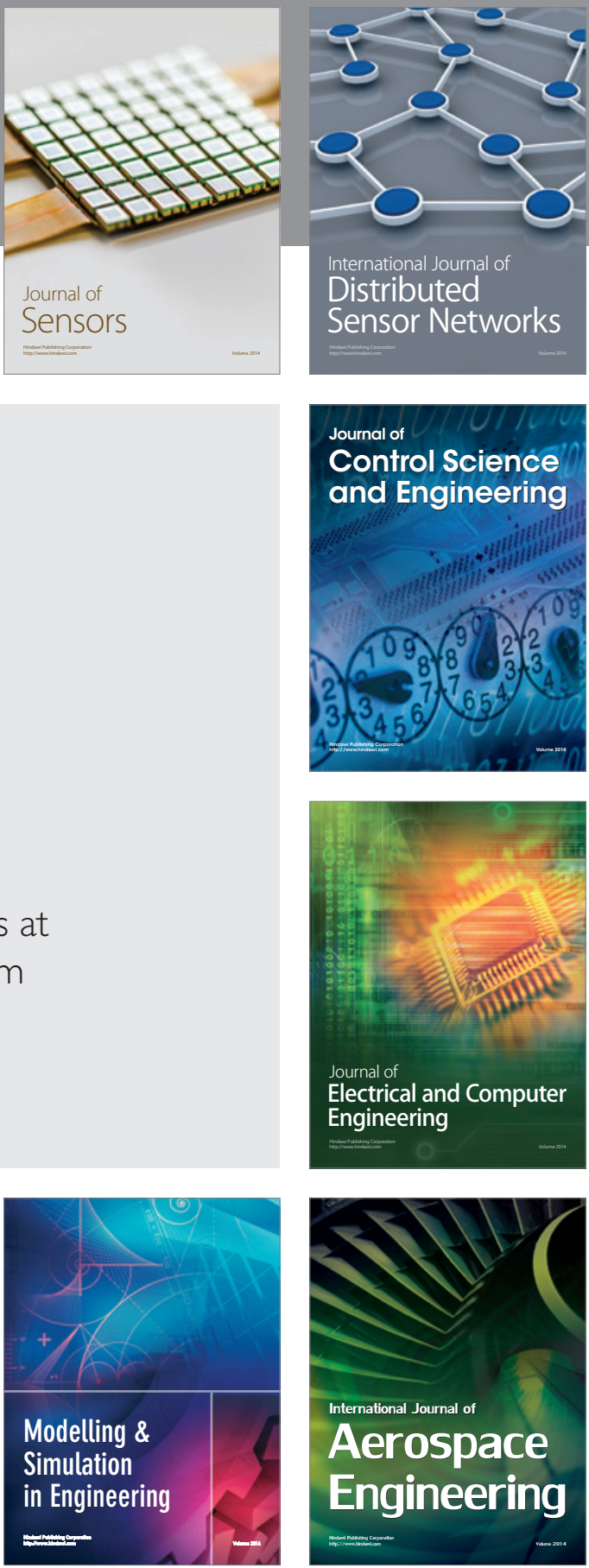

Journal of

Control Science

and Engineering
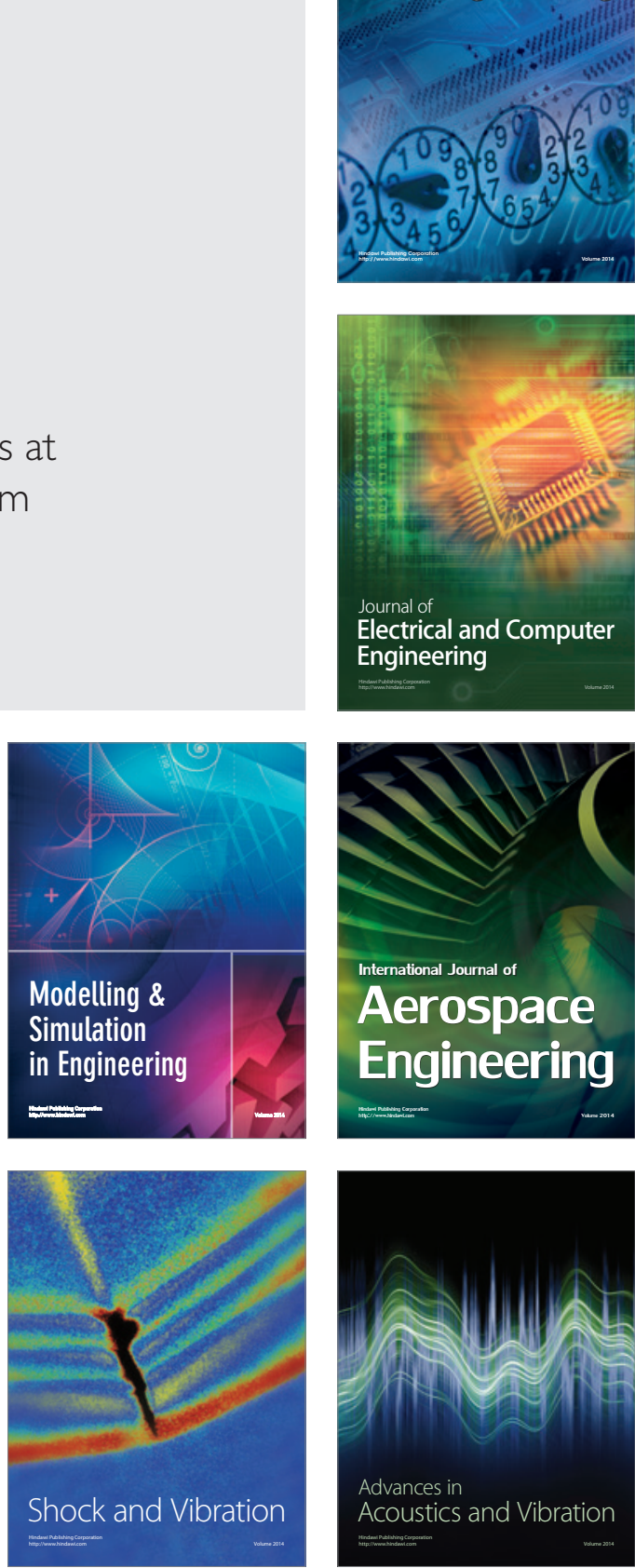